\title{
SOBRE DISCURSOS E PRÁTICAS DA BRUTALIDADE POLICIAL: UM ENSAIO INTERSECCIONAL E ETNOGRÁFICO
}

\author{
Flavia Medeiros ${ }^{1}$
}

Resumo: A partir de etnografia realizada numa repartição policial na região metropolitana do Rio de Janeiro, a Divisão de Homicídios, vou apresentar como objetos e símbolos eram acionados para reforçar posições de poder e valores de masculinidade associados à virilidade e ao uso da força. Desenvolvo uma abordagem que considera a minha experiência como antropóloga em campo e minha posição como mulher negra, tendo como interlocutores os policiais civis. Meu objetivo é discutir como os agentes do estado atuam pela "violência", fortalecendo a análise sobre mecanismos estatais de controle e marcadores sociais da diferença e, deste modo, demonstrar uma interpretação das práticas e discursos baseados de moralidades e sensibilidades, que permita refletir sobre a intersecção de posições estruturais que classificam e tratam desigualmente os sujeitos racializados.

Palavras chave: polícia; violência; racismo; etnografia; Rio de Janeiro

\section{ON DISCOURSE AND PRACTICE OF POLICE BRUTALITY: AN INTERSECTIONAL AND ETHNOGRAPHICAL ESSAY}

\begin{abstract}
From an ethnography performed at a police office in the metropolitan region of Rio de Janeiro, the Homicide Division, I will present how objects and symbols were triggered to reinforce positions of power and masculinity values associated with virility and the use of force. I develop an approach that considers my experience as an anthropologist in the field and my position as a black woman, with civil police officers as interlocutors. My goal is to discuss how state agents act by "violence", strengthening the analysis of state control mechanisms and social markers of difference, and thus demonstrate an interpretation of practices and discourses based on morals and sensibilities, which allow reflection on the intersection of structural positions that unequally classify and treat racialized subjects.
\end{abstract}

Keywords: police; violence; racism; ethnography; Rio de Janeiro

\footnotetext{
${ }^{1}$ Antropóloga, Pesquisadora de Pós Doutorado (PNPD/CAPES) do Grupo de Estudos de Antropologia do Direito e das Moralidades (GEPADIM) do Programa de Pós Graduação em Antropologia (PPGA) da Universidade Federal Fluminense (UFF). E-mail: flaviamedeirosss@gmail.com
}

Revista da ABPN • v. 11, n. 30・ set - nov 2019, p.108-129 
Resumen: A partir de la etnografía realizada en una oficina de policía en la región metropolitana de Río de Janeiro, la División de Homicidios, presentaré cómo se activaron los objetos y símbolos para reforzar las posiciones de poder y los valores de masculinidad asociados con la virilidad y el uso de la fuerza. Desarrollo un enfoque que considera mi experiencia como antropóloga en el campo y mi posición como mujer negra, con agentes de la policía civil como interlocutores. Mi objetivo es discutir cómo los agentes estatales actúan mediante la "violencia", fortaleciendo el análisis de los mecanismos de control del estado y los marcadores sociales de diferencia y, por lo tanto, demostrar una interpretación de las prácticas y discursos basados en la moral y la sensibilidad, permitiendo la reflexión sobre la intersección de posiciones estructurales que clasifican y tratan de manera desigual a los sujetos racializados.

Palabras llave: policía; violencia; racismo; etnografía; Rio de Janeiro

\section{SUR LE DISCOURS ET LA PRATIQUE DE LA BRUTALITÉ POLICIÈRE: UN ESSAI INTERSECTIONNEL ET ETHNOGRAPHIQUE}

Résumé: À partir de l'ethnographie réalisée dans un commissariat de police de la région métropolitaine de Rio de Janeiro, la division Homicide, je présenterai comment des objets et des symboles ont été déclenchés pour renforcer les valeurs de pouvoir et de masculinité associées à la virilité et à l'usage de la force. Je développe une approche qui prend en compte mon expérience d'anthropologue sur le terrain et ma position de femme noire, avec des agents de la police civile comme interlocuteurs. Mon objectif est de discuter de la manière dont les agents de l'État agissent par la «violence», en renforçant l'analyse des mécanismes de contrôle de l'État et des marqueurs sociaux de différence et, ainsi, de démontrer une interprétation des pratiques et des discours fondés sur la morale et les sensibilités, permettant une réflexion sur l'intersection de positions structurelles qui classent et traitent de manière inégale les sujets racialisés.

Mots-clés: police; violence; racisme; ethnographie; Rio de Janeiro

\section{DE PAI PARA FILHO}

Era uma das minhas primeiras visitas a Divisão de Homicídios (DH), tinha ido entrevistar um delegado plantonista. Finalizada a entrevista, ele me apresentou a sua equipe, o Grupo de Local de Crime (GELC). Na sala, um pouco mais de 10 policiais, todos homens, distribuídos sentados em cadeiras ou deitados em colchões que a mim, a primeira vista, pareciam espalhados aleatoriamente naquele espaço. Dois deles se levantaram quando 
o delegado abriu a porta e me providenciaram uma cadeira em frente a mesa que também compunha o mobiliário da sala. "Oi gente, essa aqui é a Flavia, ela é pesquisadora da UFF, ela vai explicar pra vocês, tá acompanhando nosso trabalho na delegacia...Túlio², dá uma atenção a ela aqui", disse o delegado ao me apresentar. Túlio, por ser o policial com a matrícula mais antiga, era o chefe da equipe. Diferentemente da maioria de seus colegas, ele já tinha atuado em outras lotações sendo oriundo da equipe de uma delegacia distrital em Niterói e foi apresentado pelo delegado adjunto como "o policial mais experiente do GELC”. Ele estava sentado numa cadeira próxima a mesa com um dos dois computadores utilizados pelos policiais e, como chefe da equipe, se dedicou a conduzir aquela primeira conversa.

Quando entrei na sala, ele acabara de mostrar um vídeo gravado por ele para alguns de seus colegas. No vídeo, que me mostrou posteriormente, seu filho de seis anos de idade usava óculos e proteção auricular, apontando uma pistola para um alvo de papel contra o qual realizou dois disparos. Finalizada a exibição do vídeo de cerca de 3 minutos, me explicou: "É bom ele aprender desde cedo. Esse puxou a mim: nasceu para ser polícia!". A criança tinha começado a treinar há algumas semanas, logo depois que completou seis anos. Perguntado, o policial me contou que esse não era seu único filho. Sua filha, naquele momento com 19 anos de idade, não sabia atirar e nem nunca tinha ido com o pai no stand de tiros. Ao contrário, para o policial, ela não precisaria aprender a atirar pois não tinha "a vocação" que o menino teria. Desde aquele primeiro encontro, passei a observar como o policial Túlio passava bastante de seu tempo cuidando ou falando de um objeto específico: armas de fogo. Sua experiência como policial reforçava-se na sua experiência pessoal: "eu também aprendi a atirar com meu pai" me contou.

Neste ensaio irei explorar de que forma representações sociais e raciais sobre as vítimas de policiais se relaciona com a distribuição desigual da violência, contida e codificada nas instituições do Estado e na legislação.Para isto, a partir de etnografia realizada numa repartição policial na região metropolitana do Rio de Janeiro, a Divisão de Homicídios, vou apresentar como armas e símbolos eram acionados para reforçar relações

\footnotetext{
${ }^{2}$ Todos os nomes utilizados são fictícios.
} 
de poder e papéis sociais hierárquicos, de acordo com valores de uma masculinidade que se associa a virilidade e ao uso da força. Desenvolvo uma abordagem que considera a minha experiência como antropóloga em campo e minha posição como mulher negra, tendo como interlocutores os policiais civis. Meu objetivo é discutir, sobre formas pelas quais os agentes do estado atuam normalizando a "violência". Espero assim fortalecer a análise sobre mecanismos estatais de controle e marcadores sociais da diferença e, deste modo demonstrar uma interpretação das práticas e discursos baseados de moralidades e sensibilidades, que permita refletir sobre a intersecção de posições estruturais que classificam e tratam desigualmente os sujeitos racializados.

\section{DESIGUALDADE JURÍDICA E VIOLÊNCIA POLICIAL}

A forma como Túlio valorizava os conhecimentos técnicos e práticos sobre as armas expressava suas moralidades, demarcando o valor tradicional e masculino de algo transmitido de pai para filho. Ao mesmo tempo, os instrumentos bélicos armazenados nos armários de aço que estavam naquela sala, demarcavam as fronteiras entre aqueles que compartilhava de uma ética comum, no qual o exercício do monopólio da força física para a imposição de regras era uma das práticas. A "ética policial” (LIMA, 1995a) tem em si contida de forma naturalizada, e, portanto, banal, uma série de valores baseados em marcadores sociais da diferença, refletidos na construção de uma desigualdade social estruturalmente marcada pelo sexismo e pelo racismo. Ao tomar-se como sujeitos referência de um modelo "normal" que se apropria de forma particularizada das regras para o exercício de poderes na sociedade, vemos por suas ações, características pelas quais os policiais atuavam como "empreendedores morais" (BECKER, 2008), se representando como sujeitos legítimos para criar e impor regras de acordo com seus valores e crenças.

De certa forma, é subjacente aos artigos da lei e artefatos burocráticos, que a desigualdade jurídica se apresenta garantindo a reprodução da desigualdade social e racial, explicitada em práticas e discursos de agentes estatais e nas estatísticas oficias sobre segurança pública e nos dados sobre saúde, elaborados a partir de um jogo de classificações 
entre números e categorias (MEDEIROS, 2018a). Assim, proponho refletir de que maneira se expressam valores morais nos discursos e práticas de agentes estatais, que se relacionam com a "violência" produzida contra jovens negros, favelados e periféricos, tendo como resultado a produção de mortes e prisões que atingem estes mesmos jovens

Meus interlocutores eram investigadores de homicídios e atuavam na região metropolitana do Rio de Janeiro. Como policiais acionavam uma série de símbolos e categorias que orientavam suas ações e que ao longo de um ano eu pude acompanhar a partir de trabalho de campo na sede de uma Divisão de Homicídios. Enquanto um grupo social compartilhava valores e moralidades que davam sentido a suas concepções de mundo, tanto quanto incidiam nas suas decisões profissionais. Ao manipular um aparato técnico-burocrático que tinha como ferramentas armas e inquéritos policiais, projéteis e papéis, computadores e coletes os agentes atuavam atuar entre a "guerra" e o "cartório", operando um gatilho fundamental para a reprodução do racismo estrutural e construção do racismo institucional.

\section{OS OUTROS}

Cabe destacar que tenho desenvolvido uma abordagem que considere a minha experiência como antropóloga em campo e minha posição como mulher negra, tendo como sujeitos de conhecimento antropológico os policiais civis. A etnografia sobre formas pelas quais o estado atua pela "violência" permite o fortalecimento de uma análise sobre as posições epistemológicas na construção de etnografias e sobre como a produção de conhecimento se impõe pela existência e construção do outro. Neste sentido a interpretação de moralidades pela descrição de práticas e os discursos permite o reconhecimento de

posições estruturais que classificam e tratam desigualmente os sujeitos baseados em marcadores sociais de produção de (in)diferença.

Desde uma posição peculiar demarcada pela antropologia, no qual cabe a contínua reflexão sobre sua própria atuação profissional, uma das suas principais formas de experimentar a construção do conhecimento tem se consistido na vivência e interlocução em contextos específicos com o Outro. Na minha pesquisa, esta produção de diferença se deu na interlocução com sujeitos posicionados estruturalmente nas posições de poder das 
hierarquias sociais, posto que este são agentes estatais, que se configuram como uma elite (SOUZA LIMA, 2002). Além desta posição “up” (NADER, 1972) de meus interlocutores, também tenho refletido sobre as posições na qual eu era colocada (MEDEIROS, 2018) e também como outros sujeitos que eram objeto das ações dos policiais, podiam ser estruturalmente vistos como "subalternos" (SPIVAK, 1988), às margens do Estado (DAS e POOLE, 2004), posto que sujeitos racializados, vulnerabilizados, e precarizados pelos sistemas econômicos, políticos e sociais. Especificamente, me refiro a forma como jovens negros e pobres, que compõe $73 \%$ das vítimas de homicídios no país e em geral eram também tratados como testemunhas, suspeitos e acusados de crimes, e, nessa chave identificados e classificados, elaborando distintas das formas de se produzir fronteiras e diferenciações entre aqueles outros e "outros".

Mulheres negras invariavelmente racializadas e sexualizadas (CARNEIRO, 2005; COLLINS, 2016; DAMASCENO, 2008; LORDE, 1984) não costumam ser vistas como sujeitos legítimos na produção do conhecimento, entretanto este não parecia ser meu caso no campo, onde eu era recorrentemente reconhecida como pesquisadora e professora. Ao mesmo tempo era marcante na relação comigo, e com outras pessoas negras (policias homens e mulheres, jornalistas) o acionamento de estratégias de embranquecimento, características da miscigenação imposta nas relações sociais e raciais no Brasil, fundadas no "mito da democracia racial." (NASCIMENTO, 1978). Este aspecto se expressa com o fato de eu ser regularmente chamada de "morena", e algumas vezes de "mulata", categorias acionadas para se nomear mulheres negras "de pele clara". Além disto, categorias como "nego" e "neguinho" eram usadas regularmente (inclusive por mim algumas vezes para se referir a um conjunto generalizado de pessoas) e atributos físicos e fenotípicos eram o tempo todos acionados, especialmente das pessoas negras (pretas e pardas) que circulavam pelas salas e corredores da repartição.

O que identifiquei nesta relação com o "outro", ao trabalhar pelo olhar atento e interessado às rotinas institucionais e na relação direta de interlocução e reflexão com os sujeitos que atuam no estado através do governo, e nas repartições públicas, era que por meio de suas atuações entre esses sujeitos se reproduziam, de forma consciente ou não, o 
"racismo estrutural". E, ainda, era por meio de instituições estatal do qual eles eram agentes que se elaborava o "racismo institucional". Interessada em compreender a diversidade em suas particularidades, subjetividades e especificidades, articulo a forma específica de produção de conhecimento elaborada pela antropologia, estando atenta a como as posições ditas estruturais eram estabilizadas, modificadas ou reproduzidas. É neste sentido que argumento como as ferramentas teóricas e metodológicas proporcionadas pela própria antropologia são fundamentais pois impelem ao antropólogo a elaboração contínua de um olhar crítico e reflexivo seja sobre sua própria experiência e vivência, ou pela relação intersubjetiva produzida com o "outro".

Este ensaio é fruto dessas reflexões, sobre a urgência da interlocução para aproveitar o potencial da antropologia tanto no trabalho de campo, quanto na escrita, em inquietar, e nesse sentido, em desnaturalizar certas situações, permitindo assim compreender elementos muitas vezes subjacentes a relações sociais e a estruturas de poder. Sobretudo, a partir de dados etnográficos exploro uma perspectiva interseccional que possa questionar categorias e classificações naturalizadas e refletir sobre os usos e efeitos da categoria "violência policial", considerando seu aspecto normalizado entre estes meus "outros", os policiais civis.

\section{ARMAS}

Túlio dedicava atenção especial as armas e tinha essas não apenas como uma ferramenta para o trabalho policial, mas também como fonte de lazer e prazer. "Se você atirar um dia, você vai entender o que eu estou falando" me desafiou em uma de nossas conversas quando descrevia suas idas ao stand de tiros ${ }^{3}$. Eu duvidava dessa fonte de prazer, mas aceitei o desafio. Apesar de algumas tentativas frustradas de irmos ao stand de tiros, Túlio não desistiu de me passar algumas lições lá mesmo, numa das salas na Divisão de Homicídios. Com uma pistola descarregada, ele me explicou as partes de uma arma, como desmontar, limpar, lubrificar e montar novamente. Alguns dias depois, no plantão seguinte,

\footnotetext{
${ }^{3}$ Segundo me explicaram os policias Túlio e Rinaldo, no clube do tiro, os policiais pagavam R \$130 para poder praticar 50 tiros. Na ACADEPOL, a Academia da Polícia Civil, durante o treinamento na formação, eles realizavam entre 150 a 200 disparos.
} 
considerou que eu sabia o suficiente sobre a estrutura de uma arma e passou a me ensinar como mirar: "Primeiro, junta suas mãos formando um triângulo, depois aproxima devagar do rosto sem pensar, só mirando..." A direção que as mãos tomassem era indicativo da mira. No meu caso, o olho direito. Ao olhar para a "alça de mira", eu deveria usar o olho direito para focar na "maça" e perpendicularmente alinhar meu alvo. "É por isso que a arma tem que tá limpa e calibrada. Se não tá alinhando na mira, você perde o alvo, perde o tiro.”, me explicou o policial.

Após me instruir como olhar, Túlio passou a indicar qual o posicionamento correto do corpo. Os pés deveriam estar afastados à uma distância de um passo. O joelho da frente deveria ser o oposto da mão de dominante e ficar semi-flexionado, "como se você fosse começar a dar outro passo". Aos destros, a mão direita seguraria a arma, envolvendo a empunhadura com os dedos médio e anelar e polegar. $\mathrm{O}$ dedo indicador da mão direita ficaria no gatilho. Para atirar, os braços ficavam praticamente $100 \%$ estendidos com os cotovelos levemente flexionados, punho na direção dos olhos e os ombros relaxados formando uma linha perpendicular ao chão, quando entrei na posição Túlio afirmou: "assim é a maneira mais segura de se atirar". A mão esquerda seria a “mão operacional”, servindo para apoiar a mão direita e absorver o impacto do tiro, mas também poderia ser usada para realizar outros movimentos pequenos como "limpar suor" ou "fundamentais numa situação de troca de tiros" como a troca do carregador de cartuchos. O corpo deveria se manter o máximo possível alinhado e reto, com uma leve curvatura para frente, o quadril encaixado, abdômen contraído e o peito aberto. De acordo com Túlio essa era posição perfeita para acionar o gatilho: “É assim que a gente faz no stand de tiro, é o ideal. (...) Na rua é outro esquema, depende. Se tá na operação, tem o parceiro ali pra proteger; se tá na correria é outra coisa.", falou com tom de justificativa, antes mesmo de eu fazer qualquer pergunta.

Além de práticas o atirar, ele se preocupava em cuidar das armas e era quem regularmente instruía e auxiliava outros policiais na manutenção e limpeza de suas pistolas. Um deles, o policial Bruno pediu ajuda a Túlio pois deixou sua arma, uma pistola Taurus 24/7, cair no chão durante uma "operação" para a captura de um suspeito. Túlio se disponibilizou a consertar a arma de Bruno que, de acordo com sua análise, na queda tinha 
amassado o "cão" da pistola e ficado preso no "percursor". Ambas partes, "cão" e "percursor" devem ficar travadas na pistola quando em descanso e são responsáveis pela deflagração da munição quando destravadas. O mau funcionamento desta parte da arma compromete seu uso e, inclusive, a segurança do próprio policial. Túlio descarregou a arma e enquanto desmontava a pistola, observou a quantidade de pólvora que estava no cano. “Quer ver como ele nunca limpou essa arma?” me falou. Para conferir sua hipótese, mandou uma mensagem por WhatsApp para Bruno que logo depois enviou uma gravação de áudio como resposta: "Cara, nunca limpei mesmo não. Se eu atirei cinco vezes com essa dai foi muito! Tú limpa pra mim?”, pediu Bruno. Como resposta, Túlio gravou: “Vou te quebrar essa hoje, mas depois cê tem que aprender a limpar. Vem aqui que eu te mostro como faz". Túlio não pareceu acreditar que o colega só tinha feito 5 disparos, mas preferiu não comentar. Ele falou que não tinha na repartição os instrumentos necessários para consertar a arma, e que por isso ia levar para sua casa onde poderia consertá-la. Como solução, para que o colega não ficasse desarmado, "emprestou" uma de suas armas pessoais por alguns dias.

Quando deixou sua arma cair, o policial Bruno estava descendo de uma laje que tinha subido para atirar contra o "suspeito". O homem fugiu e Bruno sabia do "risco" que corria: "eu podia ter levado um tiro ali, eu sabia, eu sabia. Mas eu tava de colete. Eu podia ter acertado um tiro... Tava difícil pra mim, mas tava difícil pra ele também!", nos contou quando foi pegar a arma com Túlio e explicou o ocorrido. Numa "operação", a possibilidade de "erro" era sempre vista como possível, pois o policial se "arriscava", expressando "coragem", um valor atrelado a uma masculinidade específica, combativa, violenta e armada

Numa “operação", o porte de uma arma era um requisito básico. Além das pistolas, os policiais também poderiam usar fuzis, submetralhadoras e até mesmo granadas. Tais ferramentas bélicas reforçavam sua participação numa "guerra" e o uso de instrumentos e vocabulários específicos pareciam reforçar estética e eticamente sua vinculação aos conflitos hostis que se desenrolavam sobretudo em favelas e periferias. Quando utilizavam fuzis, as pistolas em geral eram colocadas em coldres na lateral da coxa direita. 
No cotidiano, as armas poderiam ser vistas como uma vantagem, mas também um risco constante que trazia aos policiais preocupações e mudanças no estilo de vida, uso roupas e acessórios específicos e uma série de práticas transmitidas por conhecimentos compartilhados entre eles que, por exercício de sua função devem estar sempre armados. Porém, diferente das operações, nos quais este armamento era de uso ostensivo, no cotidiano esses policiais não poderiam ou deveriam parecer estarem armados. O porte de uma arma de fogo como me disse o policial Naldo, deve ser "escondido, quase dissimulado". Túlio também mencionara o quão importante era o "vestir" da arma, isto é, ter arma no corpo como se fosse mais uma peça da vestimenta do agente: "Se a arma não está com você ali, é como se você tivesse pelado", me explicou.

Quando não "vestidas", onde as pistolas eram guardadas também se apresentava como uma questão importante que preenchia as rotinas da vida cotidiana dos policiais. Uma policial que trabalhava no GELC, foi transferida para um setor administrativo após o diretor da DH ser informado que ela, que morava numa cidade na região do Lagos, ia e voltava de ônibus para o trabalho, carregava sua arma dentro da mochila que levava para o plantão. "Como uma policial vai ficar carregando a sua pistola na mochila dentro do ônibus? Essa não serve pra polícia..." disse o delegado.

As diferentes condições para se usar a arma e as limitações e precauções também explicitavam tal ambiguidade. Se no ônibus a arma deveria estar junto a policial, aqueles que faziam deslocamentos de motos e carros tinham outras questões. Os motoqueiros se sentiam vulneráveis pelo uso das pistolas junto ao corpo e criavam uma série de estratégias para dissimular o porte. Quando, por exemplo andavam de moto, se preocupavam em não carregar armas presas na cintura pois “Em geral não dá, vagabundo vem te abordar, você tá com a arma ali na cintura. Ele nem sabe que você é polícia, quer pegar sua moto. Ali não dá tempo de empunhar a arma, no que você puxou a mão para traz, ele já se ligou e te deu um tiro" me explicou um policial enquanto reproduzia com os braços os movimentos que descrevia.

Os policiais que andavam de carro, o que era a grande maioria deles, deixavam as armas o mais acessível possível: na cintura, entra as pernas, no banco do carona ou "no 
máximo, eu deixo uma no porta-luvas, só de garantia”, me explicou o policial Roberto que tinha pelo menos 3 armas pessoais, além da pistola que recebeu quando entrou na polícia civil.

A arma com parte da vestimenta é um recurso para dar conta daquilo que pelos policiais é descrito como um "risco constante", o de estar armado e ser reconhecido como policiais. É por isso que alguns deles preferiam andar desarmados para não por em risco a sua vida ou a de outras pessoas "na rua com minha família, eu ando sem arma" me contou Túlio, mas continuou "às vezes se a gente vai em shopping, praia, coisa e tal, eu fíco de boa. Mas, se é um lugar mais a noite, mais afastado, aí eu avalio se vou levar. Minha esposa nem sempre sabe". Outro policial, Luís, já tinha passado por uma experiência que transformou sua relação com o porte de arma: "Eu não ando mais, mas uma vez eu com minha família e dois vagabundos armados consegui sair. Depois dessa... nunca mais, nunca mais!". Se para alguns a família era o fator relevante para a decisão de "vestir"ou não uma arma, para outros era o território e a relação que eles tinham com a "bandidagem" que determinava o porte. "Aqui em Niterói eu não ando desarmado. Os vagabundos todos daqui me conhecem!” me disse o policial Roberto que trabalhava no município há cerca de 10 anos.

Um outro investigador, Valério, me explicando sobre, disse: "O meu problema é que se vagabundo tentar me matar, eu vou matar ele primeiro. Eu num quero matar ninguém não, mas se precisar, pra me defender e pra defender a minha família, eu atiro primeiro, com certeza!" Outro policial, Paulo, me descrevia como a "guerra" influenciava a sua rotina e disse: “Ou eu saio sem identificação ou eu saio de arma, eu tenho medo o tempo todo, eu tenho medo de morrer.”. Muitas vezes, os policiais compartilhavam suas concepções sobre quando saíam armados ou não, : "Se estou só com minha mulher, eu uso sim. Mas se a gente tá com nosso filho eu nem uso, a gente acha melhor assim”, explicou Leon. Como descrevi, esta era uma questão especialmente quando estavam com seus familiares, posto que no deslocamento de casa ao trabalho, e vice-versa, em geral sempre estavam com as armas. Suas concepções expressavam uma ambiguidade e davam conteúdo a forma como aqueles que trabalhavam em uma situação classificada por eles como de 
"guerra" tinha como "campo de batalha" a própria cidade em que viviam com suas famílias.

Essa ambiguidade se enfatizava diante das condições para quem vestia uma arma no dia a dia e na atividade policial: "Quando você tem uma arma ali, você não vai esperar (atirarem primeiro), você vai atirar", me explicou Roberto. "Tem vezes que o bicho pega", eles diziam. Um desses casos a mim relatado foi a troca de tiros que acidentou o policial Normando. Ele realizava um "bico" de segurança de banco em 1991 e me descreveu "aquela foi a primeira vez que tomei um tiro. Ali eu achei que eu ia morrer. O vagabundo acertou meu abdômen, pegou baço e fígado. Fiquei em coma dois dias, 45 (dias) no hospital". Depois de recuperado, normando voltou a atuar na polícia e apesar de ter sido atingido enquanto fazia um trabalho extra, vinculava aquilo a sua atividade na polícia: "ali eu aprendi o que era ser policial".

Situações com armas que resultavam em "disparos acidentais" também eram comuns e alguns casos me foram relatados, como quando o policial Júlio estava sentando numa viatura quando um dos colegas disparou acidentalmente atingindo sua perna esquerda. "Depois disso eu entendi, ser policial é estar sempre na linha de fogo" me disse. Pude observar mais de uma vez esse policial chamando a atenção de colegas, especialmente os mais jovens quando estes se despiam de suas armas e as colocavam sobre superfícies de apoio. Uma vez, estávamos na sala da equipe de investigações conversando sobre dois inquéritos que estavam sendo investigados por ele, quando o policial Felipe entrou, tirou a arma do "coldre" preso a sua cintura e a posou destravada sobre a mesa que ficava posicionada no centro da ampla sala. O cano da arma ficou apontado na minha direção, que estava sentada do lado oposto a Júlio. Este policial então, com as pontas dos dedos, girou levemente a arma, virando o cano na direção de Felipe e mudando um pouco seu tom de voz falou: "Oh cana, vira esse ferro pra lá!”. Era uma regra tácita entre os policiais que as armas dentro da repartição deveriam estar sempre travadas e nunca apontada a outras pessoas, a não ser que houvesse a intenção de uma ameaça ou demonstração de força.

\section{"COISAS DE POLÍCIA"}


O dia a dia dos policiais era repleto de mediações por objetos, muitos deles que se configuravam como indicadores materiais de sua condição social por serem bens de propriedade exclusiva de um policial civil. A aquisição destes bens, e sua manipulação, dependia de regras e acabava por representar as escolhas dos policiais diante da diversidade de situações nas quais se encontravam. As armas eram o mais emblemático objeto nesta construção, visto sua finalidade: exercer poder pela violência contra o outro. Como sabiam e repetiam os policiais: "ter uma arma é ter nas mãos a possibilidade de matar" e manipular uma arma era escolher usar um instrumento cujo objetivo vem junto com um risco. $\mathrm{O}$ porte de armas era autorizado pela "carteira funcional", documento de identificação que comprovava o status social de policial. Aos profissionais, quando formados, além da carteira, era também entregue pela Polícia Civil o distintivo, um brasão de metal com fundo vermelho para delegados e azul para agentes. Carteira funcional, distintivo e arma, conjugados, funcionavam como a materialidade da legitimidade concedida pelo Estado àqueles agentes.

Outro objeto cuja importância era discutida e registrada pelos policiais, eram os coletes de proteção, disponibilizados individualmente a cada um deles pelo Estado. Ao usarem os coletes ${ }^{4}$, os policiais reclamavam dos desajustes e incômodos no uso desta ferramenta: "o colete já pesa, então tem quer ser justo no corpo", o que facilitaria na sua mobilidade. Também destacavam certa insegurança que sentiam quando usavam um colete maior do que o seu tamanho: "no suvaco, fica abertão aqui (apontado para a região das axilas), o colete tem que ser certinho, proteger o peito e as costelas", falou outro policial, reclamando do tamanho inadequado do seu coleto e do desconforto provocado por um

\footnotetext{
${ }^{4}$ Até meados de abril, quando realizei a última ida a "local de crime" com a equipe do GELC, a repartição ainda não havia recebida coletes à prova de balas tamanhos $\mathrm{P}$ ou $\mathrm{M}$, adequados para o tamanho de meu corpo, assim como de todas as mulheres que lá trabalhavam. Os únicos coletes disponíveis eram tamanho $\mathrm{G}$, o que impedia às policiais e a alguns de seus colegas homens de usarem este tipo de proteção. "Os homens médios usam o G, mas fica desconfortável e inseguro" me explicou certa vez um policial que não gostava de usar o colete maior do que o seu tamanho, mas que era obrigado por sua lotação no GELC. Algumas semanas depois, no começo de abril, novos coletes chegaram e aqueles que ainda não o tinham feito, foram até a Cidade da Polícia para retirar o seu. Nunca me foi oferecido um colete que não estivesse sendo usado por algum policial e nunca soube da chegada de coletes excedentes para eventuais usos por testemunhas em reconstituição, policiais em treinamento ou visitantes como consultores, jornalistas ou pesquisadores.
} 
colete desajustado: "[o colete] é ruim porque perde a agilidade. Eu tô com uma arma, uma pistola no coldre, um fuzil pendurado... atrapalha mais que ajuda” explicou-me Túlio.

Alguns policias compravam coletes personalizados, considerados por eles mais seguros. Este eram um dos produtos mais caros com preços que variavam de $\mathrm{R} \$ 300$ a $\mathrm{R} \$ 1000$. Bonés, cintos operacionais camisetas, bottons, decalques de tecido para ser grudado a velcro nos coletes e calças operacionais, coturnos todos da cor preta eram outros dos diversos produtos destinados aos policiais. Como consumidores, eles muitas vezes combinavam de ir juntos à Cidade da Polícia ou a "Loja do Militar" na região Central da cidade do Rio de Janeiro, onde poderiam adquirir tais objetos. Ainda, na DH várias produtos chegavam pelo contato de policiais mais antigos, como o inspetor Cardoso, que revendia tais produtos diferenciados a este público, a grande maioria deles com logotipos da Polícia Civil (ver imagens 1 e 2). Objetos identificados com o brasão e as inscrições oficial da Polícia Civil que eram usados repetidamente e que não devem "ser simplisticamente interpretados como uma reprodução fiel da ideologia policial" mas como uma "iconografia, orgulhosamente disposta nas roupas dos oficias, apresenta algumas pistas de como eles veem suas vidas em relação ao seu público" (FASSIN, 2013, p. 8).

Não apenas nas roupas, uniformes e acessórios dos policiais estes signos também estavam nas instalações físicas como ao redor do prédio desde a entrada, adesivos nas portas das salas, nas viaturas, em todos os documentos oficiais. Um dos maiores deles se encontrava na placa de entrada, informando aos que passavam na rua qual repartição da burocracia estava funcionando no interior dos limites daquele portão. No topo da placa estava descrito em branco e azul as inscrições: POLÍCIA CIVIL DO ESTADO DO RIO DE JANEIRO / DEPARTAMENTO GERAL DE POLÍCIA ESPECIALIZADA / DIVISÃO DE HOMICÍDIOS / NITERÓI - ITABORAÍ - SÃO GONÇALO. Outros dois grandes adesivos estavam colados nas partes externa e interna do hall de entrada para serem a primeira coisa a ser notada por aqueles que entrassem no prédio da repartição. 


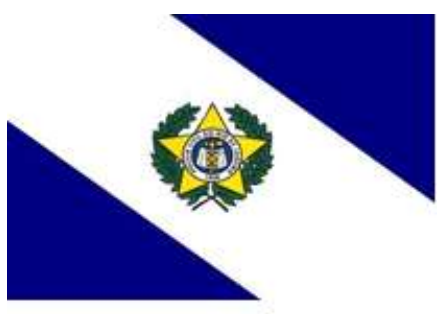

Imagem 1 - Bandeira da Polícia

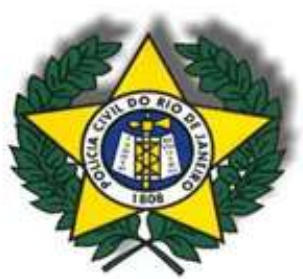

Imagem 2 - Brasão da Polícia

Bandeira (imagem 1) e brasão da Polícia Civil do Estado do Rio de Janeiro (imagem 2) foram criados por um delegado de polícia e em 1987 oficialmente aprovados pelo Governador Moreira Franco. A bandeira serve apenas como suporte para o brasão, colocado centralmente sobre um fundo é em cor azul-celeste sobreposto por uma faixa diagonal branca. É no brasão que se encontram os elementos chaves selecionados pelo delegado e reproduzidos pelos policiais para estabelecer uma identidade visual para a Polícia Civil. Constituído de um escudo de fundo também azul, em primeiro plano se vê duas tábuas brancas com inscrições de números romanos do I a XII, representando a "Lei das Doze Tábuas" que seriam a origem da lei no antigo Direito Romano considerado o marco inaugural de valores republicanos ocidentais como o "direito civil" e protocolos judiciais. A utilização de tal símbolo demonstra o interesse em associar a PCERJ ao mito de origem do chamado "direito ocidental".

Entre as duas tábuas, se centraliza um fasces lictoris de ouro, forma de se referir em latim a uma espécie de machado que tem sua origem remetida aos "etruscos" que viveram durante o período do Império Romano. Esta ferramenta simbolizada no brasão da PCERJ seria usada pelos lictors, cidadãos ligados ao poder e à autoridade que se utilizavam-de fasces, um feixe de varas amarradas ao preceder a passagem de figuras públicas, como magistrados, em cerimônias militares ou jurídicas oficiais. Os fasces lictoris vinham acoplados pelo machado, sendo esta a forma simbolizada no brasão, e passou a ser usado em diferentes instituições nos países euro-americanos como símbolo de justiça e demonstração do poder sobre a vida e a morte.

A Polícia Civil do Rio de Janeiro não é a única instituição a utilizar tal símbolo, que tem sua versão aplicada em diversas representações em instituições como nos Estados Unidos e na França, em ambos países simbolizando o poder da justiça. O fasces lictoris, ou 
em italiano fascio littorio, também serviu de inspiração principal para Benito Mussolini e seus companheiros em Milão, que se apropriam deste símbolo para em 1919 inaugurar o movimento "Fascio de Combatimento" que deu origem ao regime fascista ${ }^{5}$. Uma das principais estratégias estéticas e políticas do fascismo era o uso da "romanidade" como mito de origem, remetendo a Itália do começo do século XX e ao Império da Antiguidade Romana. Tal mitologia fascista representa na "disciplina" sua principal virtude, e esta era pressuposto do "poder", principal valor da nação que pelo regime ditatorial buscou implementar um "imperialismo fascista" (GIARDINA, 2008)

O brasão ainda conta com uma faixa branca ao redor do escudo de fundo azul onde estão sobrepostos tábuas e fasces lictores. $\mathrm{Na}$ faixa branca em letras pretas na parte superior se lê, "POLÍCIA CIVIL DO ESTADO DO RIO DE JANEIRO" e na parte inferior o número "1808”, referindo-se ao ano de 1808 quando foi criada a Intendência Geral de Polícia, após a chegada da família real e que é considerada o ano de criação da Polícia Civil (HOLLOWAY, 1993, p. 46). O escudo está centralizado sobre uma estrela de ouro de cinco pontas, representando a autoridade policial, ao remeter-se as estrelas utilizadas por xerifes e delegados. A estrela se apoia numa coroa de louros verdes e serve com forma de Polícia Civil de se laurear, reconhecendo a si própria como merecedora de tal triunfo. Atualmente, a Polícia Civil representa este brasão como a "Identidade Organizacional" trazendo pelas cores branco, verde e amarelo quais são seus valores, sua visão e sua missão representadas.

Os símbolos oficiais não eram os únicos usados pelos policiais para representar-se enquanto tais. Além do brasão da PCERJ, outros símbolos também apareciam nos uniformes e acessórios ou decoravam as salas, viaturas, murais, fundos de tela de computadores e celulares, etc. Um dos símbolos mais comuns era a "águia”, que na PCERJ se refere primordialmente as "Operações Aéreas", mas que, representada com um raio no

\footnotetext{
${ }^{5}$ Em relação ao debate sobre a influência da estética romana e do fascismo e sua simbologia na cidade do Rio de Janeiro ver BERTOLUCCI, 2015.

${ }^{6}$ Em relação a essa representação, um grupo de policiais civis tem se organizado com outros segmentos, num grupo autodenominado "Policiais Antifascismo" que assim se descreve na rede social facebook: "Na contramão do pensamento hegemônico de uma policia a serviço do Estado brasileiro, policiais civis, militares e guardas municipais se reúnem para construir uma policia mais próxima do povo. A serviço do povo! Numa relação dialógica que compreenda suas ações na garantia dos direitos. Policiais num caminho contrário ao pensamento e ação que teima em desumanizar e tratar o povo como inimigo. Policiais na contra ordem do fazer, historicamente, segurança pública nesse país!”. Nas últimas eleições, este grupo lançou candidaturas políticas e tem se articulada como um alternativa ao debate da segurança pública, desprezando a contradição presente na própria ideia de uma polícia antifascista.
} 
bico ou nas patas simbolizava "coragem", "força" e o "poder". Outro, igualmente comum, era a "caveira", utilizada principalmente pela CORE (Coordenadoria de Recursos Especiais) , que é cruzada por fuzis e atravessada de baixo para cima por um punhal, denotam o "poder sobre a morte", semelhante ao símbolo que ficou consagrado pelo Batalhão de Operações Especiais (BOPE) da PMERJ. Além dos símbolos gráficos, a Polícia Civil também conta com um hino, no qual se referência como a "gloriosa"7 e que vez ou outra era lembrando pelos agentes, especialmente os da "turma nova" que tiveram que repetidas vezes cantar o hino durante curso de formação na Academia de Polícia, a Acadepol.

\section{RISCO E HONRA}

Estes objetos materiais inscritos com símbolos físicos correspondiam ao status social e aos valores de masculinidade e poder que aderiam os policiais ao passar a ter acesso a uma série de bens simbólicos. Depois de aprovados e investidos do cargo, os policiais passavam a ter uma nova posição social e adquiriam diversos atributos que constantemente os lembravam que eles eram "diferentes demais". Tal distinção se dava devido a sua função como agente da polícia e como membros desta corporação. Para os policiais, a diferença entre eles e os outros não se limitava ao horário de serviço, mas se estendia durante o dia a dia nos mais diversos aspectos da vida. Desde que se tornaram policiais, coisas rotineiras como deslocamentos, idas a bancos ou restaurantes e outras atividades especialmente em locais públicos, foram modificadas. Os policiais consideravam que para eles era "perigoso viver uma vida comum" e que muitos lugares e situações eram para eles "arriscados" e “inseguros" e representavam que só estavam protegidos "ou em casa, ou na base".

A constante sensação de "risco" que tinha relação com a sua condição social enquanto policiais indicava também sua representação do público como hostil. Para os policiais, "a sociedade" tinha que "conhecer a polícia" e aprender que "o policial civil trabalha para a sociedade", demarcando continuamente a separação deles do resto da

\footnotetext{
7 "Gloriosa Polícia Civil/ Em defesa de quem precisar/Gloriosa Polícia Civil/Nossa Lei sabes honrar/Pelos céus deste Estado formoso/Teu estandarte tremula altaneiro/Baluarte da Lei e da Ordem/Salvaguarda do Rio de Janeiro/Gloriosa Polícia Civil/Em defesa de quem precisar/Gloriosa Polícia Civil/Nossa Lei sabes honrar/Pelos céus deste Estado formoso/Teu estandarte tremula altaneiro/Baluarte da Lei e da Ordem/Salvaguarda do Rio de Janeiro/Policial Protetor/Guardião da Sociedade/Sentinela avançada/Defensor da liberdade/Policial Protetor/Guardião da Sociedade/Sentinela avançada/Defensor da liberdade"
} 
população. Além disso, o aparente temor que expressavam se referia àqueles que denominavam de "clientes": "os bandidos daqui da área me conhecem todos!" como me disse o policial Roberto. As diferentes formas de expressão do "medo de ser morto" ainda se completava com a concepção da imprevisibilidade da polícia, vista como consequência da adesão naquela corporação. Porém, quanto mais um agente aderia a malha corporativa (LIMA, 1995a) menos imprevisível se tornava para ele a "política da polícia". Me parece que como a mobilização continua de medos e incerteza na/da Polícia exercia "uma tripla função para os agentes policiais: isto reforça a solidariedade grupal; protege o segredo profissional; e justifica reciprocidade" (FASSIN, 2013, p.8).

No decorrer deste ensaio busquei descrever como os policiais civis que atuavam na investigação dos homicídios expressavam seus interesses se vinculando com/por objetos, conformando um denso entremeado de relações sociais e materiais que eram mantidas pela construção continua de mútuos interesses e adesão a certas regras e valores. Estes valores que o faziam "ser polícia", por sua vez, estavam expressos na masculinidade, no uso de armas, na participação na "guerra" e no distanciamento de perspectivas em relação à sociedade. Entre os policiais, por sua vez, se fortaleciam laços de "solidariedade" que expressavam empatia aos interesses da corporação. Apesar das tensões e conflitos "políticos", os agentes demonstravam forte coesão interna que se pautava na manutenção e reprodução de segredos e no compartilhamento de conhecimentos práticos, demonstrando as relações de reciprocidade estabelecidas por estes agentes que conformavam numa forma de vida específica, relacionando-se numa malha corporativa pela qual se dava a "política da polícia".

\section{A BRUTALIDADE POLICIAL}

As linhas de vidas dos policiais se expressavam em certos valores morais e por meio de "símbolos" e "interesses" que estabeleciam vínculo de reciprocidade e coesão entre eles. Explicitados no tecer das relações que os conectavam com objetos e outros bens materiais, os policiais constituíam uma malha que os inseria e mantinha como membros daquela corporação e portanto, com acesso a objetos específicos que, inclusive os constituíam como 
policiais tais como armas e distintivo, e com símbolos e valores morais compartilhados entre eles.

Se do ponto de vista das relações de gênero, o contexto de pesquisa era marcado pela masculinidade, no que concerne a sua racialização, homens e mulheres policiais não diferiam tanto ${ }^{8}$. Eles eram majoritariamente brancos, de estatura média, magros e de cabelos lisos. Curtos para os homens e longos para as mulheres. Apesar de uma parte dos policiais serem pardos, poucos se identificavam como negros. Apenas uma parte minoritária de pretos trabalhava naquela repartição e considerando a divisão de homens e mulheres, tinha a grande maioria dos homens brancos, enquanto quase metade das mulheres eram negras (incluindo aqui, pardas e pretas). Proporcionalmente, como já eram poucas as mulheres atuando como agentes na $\mathrm{DH}$, se tornavam ainda pouquíssimas as mulheres negras que, como eu, frequentavam aquela repartição. Algumas jornalistas e policiais (três no cartório e duas em um Grupo de Investigação), devido a sua excepcionalidade e, de certa maneira, eventualidade, eram destacadas e frequentemente reconhecidas pelo "belo trabalho".

A construção do meu lugar como antropóloga no campo se deu ao conhecer e acessar aquele mundo, me ajustando a ele na medida em que passei a conhecer as regras e os valores dos policiais, bem como eles reconheciam os meus. Entre os meus interlocutores e eu havia diferenças fundamentais que se expressavam de diversas formas, especialmente quando considerados nosso gênero, cor de pele e grau de formação escolar. Se para eles, tais diferenças eram parte das observações cotidianos que faziam sobre mim, eu as tomava como parte do exercício que, como antropóloga, me propus a realizar ao interagir e conhecer aquele outro. A minha presença impunha mudanças na forma como eles atuavam, que aos poucos, ao passo que nos conhecíamos, iam se dirimindo ou alterando. Por outro lado, a minha aparência, jeito, rotina, humor eram todos objetos de avaliação que os informavam e confundiam no nosso exercício mútuo de controle e análise de impressões.

Era nesse jogo que a naturalização da violência policial também se expressava como quando continuamente, eu negociava acessos, posições e oportunidades para exercitar

\footnotetext{
${ }^{8}$ Durante o período da pesquisa, a DH contava com cerca de 170 agentes.
} 
minha observação. Certa vez, o grupo de investigadores que eu acompanhava mais diretamente ia realizar uma "diligência" na região do Alcântara, em São Gonçalo para indiciar uma testemunha de um caso de "homicídio" cuja vítima era um homem, pardo, 53 anos, comerciante e cujas "linhas de investigação "eram "dívida", "acerto de contas" e "vingança". Enquanto se preparavam para sair, perguntei ao policial Roberto se eu poderia acompanhá-los. Inicialmente, ele disse que sim em concordância com Bruno, Dirceu e Jorge, todos homens brancos entre 30 e 45 anos que disseram que "o local é tranquilo", o que eu também de certa maneira sabia. Cerca de dez minutos depois, Roberto virou para mim e falou: "Acho melhor você não ir não, foi mal. Pode ser perigoso!", “Tudo bem, tranquilo. Você que sabe!" respondi. Uma hora e meia depois, quando eles voltaram para a "base", Jorge comentou comigo: "Ué, senti sua falta. Por que você não foi” e eu expliquei: "O Roberto embarreirou, disse que era perigoso.". E Jorge exclamou: "Perigoso nada, negócio limpo, tranquilo". Outra vez, porém, a "diligência" foi na região do Arsenal, também em São Gonçalo. Novamente, perguntei se poderia ir, e desta vez eu considerava aquele como um lugar de "risco" por saber da presença conflituosa de comércio armado de substâncias psicoativas. Roberto me respondeu: "Só se você quiser ir mesmo...", e como numa ameaça complementou: "mas fica sabendo, se você levar um tiro, eu vou botar uma arma na sua mão!”. Nem só pelo risco de ser atingida, mas pela falta de confiança, e eu não quis ir mesmo.

A explicitação de que eu poderia ser alvo de uma prática altamente comum entre os policiais, a de implantar armas em determinadas vítimas para legitimar suas mortes e desumanizar as suas existências, demonstrava de tal forma a concepção sobre certos sujeitos em relação a violência policial que se expressa em espaços nos quais se vinculava uma estratégia de "guerra", corrente na gestão de espaços urbanos construídos como territórios de "risco" e, por isso, vulneráveis ao arbítrio dos poderes "de/da polícia" (MEDEIROS, 2019a; FASSIN, 2013; AMAR, 2013).

Assim, aqueles que eram atrapados na rede de captura, alvo de sua ação como malha corporativa que visa a manutenção da estrutura desigual da sociedade brasileira (LIMA, 1995a), eram classificados como "clientes" e tratados, ora como suspeitos, ora como 
testemunhas e porventura vítimas dos homicídios investigados. Isto porque os policiais enquanto grupo social também delimitava quem eram os seus outros, neste caso, os jovens negros. Apesar de nas práticas rotineiras não estarem explicitadas racializações, os policiais agiam através de "imagens de controle" (DAMASCENO, 2008) numa relação mediada por diferentes formas de mobilizar a violência. De certa forma sua atuação parecia ser expressar pelo "colorblindness" (CRENSHAW, 1989), uma espécie de "cegueira a cor", conceito que nos ajuda a entender como ainda que não explicitem a cor como um fator para suas ações, supostamente dentro de um mito uma equidade racial, as decisões baseadas em definições de racializações se colocavam. Assim as manifestações de poder tomavam certas categorias sociais e raciais como algo relacional não apenas de cor de pele, mas a raça enquanto práticas e valores sobre territórios específicos. O argumento do "colorblindess" confere uma plasticidade a forma como a violência de estado age de forma racializada produzindo um tratamento desigual e impossibilitando o reconhecimento digno das humanidades e subjetividades desses que são criminalizados e mortos pelo estado (PINHO, 2019).

É portanto, considerando que a polícia é a violência organizada dentro da forma Estado que proponho pensar, seja pelas armas, pelos símbolos ou pela forma como se engajavam em suas relações, que falar da noção polissêmica de "violência policial" (MEDEIROS e EILBAUM, 2015) é em alguns sentidos redundante, posto que esta é a finalidade social, política e histórica da polícia, a de produzir sobretudo contra corpos e territórios negros e pobres uma ação violenta, baseada no controle e no poder. Diante de ações policiais que se repetem e reforçam meios de eliminação, extermínio e controle, sugiro então pensar na ação ação policial excessiva como uma "brutalidade", uma forma de reafirmar seus valores de masculinidade, tanto quanto reforçar seus laços de honra, dirimindo riscos e demarcando fronteiras simbólicas e morais entre aqueles que os policiais consideram como sujeitos e os outros tantos que não.

\section{REFERÊNCIAS BIBLIOGRÁFICAS}

AMAR, Paul. O arquipélago de segurança: estados de segurança humana, políticas de sexualidade e o fim do neoliberalismo. Rio de Janeiro: EdFUFRJ, 2018.

BERTOLUCCI, 2015. Assembleia do Rio tem símbolos que podem ser da Roma Antiga ou referência ao fascismo Em postes, calçadas e adornos do Palácio Tiradentes e entorno, é possível observar desenhos do 
regime do italiano Mussolini http://oglobo.globo.com/rio/rio-450/assembleia-do-rio-tem-simbolos-quepodem-ser-da-roma-antiga-ou-referencia-ao-fascismo-16441700

BECKER, Howard S. (1963). Outsiders. Estudos de sociologia do desvio. Rio de Janeiro: Zahar. 2008

CARNEIRO, Aparecida Sueli. A Construção do Outro como Não-Ser como fundamento do Ser. Tese (Doutorado em Educação) Universidade de São Paulo, São Paulo, 2005.

COLLINS, Patrice Hill. Aprendendo com a outsider within: a significação sociológica do pensamento feminista negro. Revista Sociedade e Estado - Volume 31 Número 1 Janeiro/Abril 2016. http://dx.doi.org/10.1590/S0102-69922016000100006

CRENSHAW, Kimberly Demarginalizing the Intersection of Race and Sex: A Black Feminist Critique of Antidiscrimination Doctrine, Feminist Theory and Antiracist Politics, p. 139 - 67: 1989

DAMASCENO, Janaína. O corpo do outro. Construções raciais e imagens de controle do corpo feminino negro: O caso da Vênus Hotentote. In.: Anais do Fazendo Gênero 8 - Corpo, Violência e Poder. Florianópolis, $2008 . \quad$ Disponível em: http://www.fazendogenero.ufsc.br/8/sts/ST69/Janaina_Damasceno 69.pdf

DAS, Veen.; POOLE, Deborah. (Ed.). Anthropology in the margins of the state. Santa Fe: School of American Research Press, 2004.

FASSIN, Didier. The Moral World of Law Enforcement. The Occasional Papers of the School of Social Science. Unpublished. PAPER NUMBER 49. MARCH 2013.

GIARDINA, Andrea. O mito fascista da romanidade. ESTUDOS AVANÇADOS 22 (62), 2008

HARAWAY, Donna. Saberes localizados: a questão da ciência para o feminismo e o privilégio da perspectiva parcial. Cadernos Pagu (5), Campinas- SP, Núcleo de Estudos de Gênero - Pagu/Unicamp, 1995, pp.741http://dx.doi.org/10.1590/S0104-83332011000100002

HOLLOWAY, Thomas. Polícia no Rio de Janeiro: repressão e resistência numa cidade do século XIX. Rio de Janeiro: Editora da FGV, 1997.

HOOKS, bell. From margin to center. Boston: South End Press, 1984.

KANT de LIMA, Roberto. A polícia na cidade do Rio de Janeiro, seus dilemas e paradoxos. Rio de Janeiro: Editora Forense, 1995a

Da inquirição ao Júri, do Trial by Jury à Plea Bargaining: modelos para a produção da verdade e a negociação de culpa em uma perspectiva comparada (Brasil/EUA). Tese apresentada ao concurso de professor titular em Antropologia. Niterói: Universidade Federal Fluminense, $1995 b$

LORDE, Audre. Sister outsider. New York: The Crossing Press, 1984

MEDEIROS, Flavia. Linhas de investigação: uma etnografia das técnicas e moralidades numa Divisão de Homicídios na Região Metropolitana do Rio de Janeiro. Rio de Janeiro: Autografia, 2018a.

MEDEIROS, Flavia Adversidades e lugares de fala na produção do conhecimento etnográfico com policiais civis. Cadernos De Campo (São Paulo 1991), 2018b. 26(1), 327-347.

MEDEIROS, Flavia e EILBAUM, Lucía Quando existe "violência policial"? Direitos, moralidades e ordem pública no Rio de Janeiro. In.: Dilemas, Rio de Janeiro, UFRJ, 2015, Vol. 8, n.3:407428.

NADER, Laura. "Up the Anthropologist. Perspectives Gained from Studying Up" In: Dell H. Hymes (Ed.) Reinventing Anthropology. New York, Pantheon Books, 1972. p. 284-311.

NASCIMENTO, Abdias. O Genocídio do negro brasileiro: processo de um racismo mascarado. Rio de Janeiro: Paz e Terra, 1978.

PINHO, Osmundo.O corpo do Homem Negro e a Guerra dos Sexos no Brasil. In.: RESTIER, H. e de SOUZA, Rolf (orgs.) Diálogos contemporâneos sobre homens negros e masculinidades. São Paulo: Ciclo Contínuo Editorial, 2019.

SOUZA LIMA, Antônio Carlos de. Introdução. In. SOUZA LIMA, Antônio Carlos de. (org.) Gestar e Gerir: estudos para uma antropologia da administração pública no Brasil. Rio de Janeiro: Relume Dumará, 2002.

SPIVAK, Gayatri Chakravorty. "Can the Subaltern Speak?" Marxism and the Interpretation of Culture. Ed. Cary Nelson and Lawrence Grossberg. Urbana: U of Illinois P, 1988. 271-313.

Recebido em: 30/09/2019

Aceito em: 30/10/2019

Revista da ABPN • v. 11, n. 30 • set - nov 2019, p.108-129 